\title{
An Exploratory Study on the Difficulties Faced by First-Generation Learners in Writing Skills
}

\author{
K. Perumal \\ Vellore Institute of Technology, Chennai \\ Ajit. I \\ Vellore Institute of Technology, Chennai
}

\begin{abstract}
Language is a complex process, especially its written mode. To write better, one must be well acquainted with vocabulary and contextual expressions. The difficulties faced by the first generation learners of English in India are numerous because exposure is a bigger issue. The remedies for their difficulties are elaborately discussed in this paper. The aim is to throw light on the obstacles of the first generation learners at the tertiary level who had studied English as the second language or as a medium of instruction at the school level. Eighty such participants were selected using random sampling technique and a semistructured interview was conducted. A mixed-method approach was used and a questionnaire was administered. The present study identifies difficulties in writing skills faced by first generation learners. And also, this paper focuses on the impact of difficulties in writing skills on them. Additionally, remedial measures to enhance writing skills are also discussed.
\end{abstract}

Keywords: first-generation learner, method, writing skills, teaching and learning

\section{INTRODUCTION}

English is considered to be a very critical, global language. Language skills can be divided into four which are listening, speaking, reading, and writing. Writing is an essential skill among them. Though we study English from primary school up to secondary school, many of us cannot speak the language fluently and write correctly owing to insufficient vocabulary, lack of knowledge in grammar and inadequate learning material and sources in the classroom. Most of the rural students cannot speak and write fluently in English as a result of their inhibition. Although a majority of them have good content and knowledge in the subject, they find it difficult to express themselves in speaking and writing.

English, being a global language, is essential if we want to make a career in today's multinational setup. Although writing is difficult, it is a very crucial skill. Good Writing in English has become the need of the hour. However, students who are desirous of succeeding in the global market lack speaking and writing skills. Daniel (1996) says, "Writing is a system of more or less permanent marks used to represent an utterance in such a way that it can be recovered exactly without the intervention of the utterance". Jack (2013) argues that students' attitudes towards writing skills, background, learning context, content, material, and teacher's methodologies to teach writing skills are the key factors affecting writing skills. Of all the language skills, writing is the most important and we can express our ideas, feelings, emotions and 
information to others through writing. This skill is one of the best ways to convey ideas or messages. Though writing skill is complex and challenging to learn, it is an art in itself. The skill is developed through exposure and practice in various contexts and situations. While learning English as a second language, writing is much focused on the process itself. Many studies focus their attention on pedagogical aids adapted by teachers and also the strategies adopted by learners to improve their writing. In the traditional classrooms where the teacher guides and controls the classroom activities, the learners' writing is strictly performed in a controlled environment by means of drilling and rote-learning.

\section{SURVEY OF LITERATURE}

This section reviews some of the studies which are interrelated to the present study. Akbar. $\mathrm{M}(2018)$ examined the problems faced by the learners in his study tiled Problems affecting $L_{2}$ Learners' English Writing: A Study of Public Sector Colleges in Hyderabad City, Sindh, Pakistan. The experiment, conducted with 160 students and 5 teachers, followed the sequential mixed-method model of Creswell (2009). Data was collected through a questionnaire and the results indicated that the least frequent writing difficulties faced by $\mathrm{L}_{2}$ learners were due to poor academic background, mother tongue interference, lack of vocabulary, a significant class issue, lack of knowledge in grammar structure and insufficient sources in the language classroom.

Gaikwad. J(2018) conducted an experimental research to improve the writing skills of Commerce students. Teaching Learning Materials (TLM) formed part of the research tool to improve their writing skills and motivation in writing. At the end of the study which comprised a plethora of learning activities the participants' skills in paragraph writing and essay writing and using grammatical components were found to be developed. The results revealed that the TLM method improves students' creative thinking and writing skills.

Bakeer, A.M (2018) conducted a case study of Information and Communication Technology (ICT) and social media in writing courses at Al-Quds Open University to enhance undergraduate students' writing skills and identify difficulties in writing in English. The effects of ICT and social media had positive impact on improving students' writing skills.

Gomathi R.D (2017) researched under the title Improving the English Writing Skills of College Students through Activity Learning and stated that activity learning environment in the classroom was found to develop writing skills and creative thinking skills of the students.

Justina. M (2016) published a study titled Use of WhatsApp to Enhance Reading and Writing Skills at Undergraduate College Level. It attempted to improve writing and reading skills with the help of select messages and to reduce anxiety in writing for regional medium learners. The investigator reported that the use of social media had positive effects on improving writing skills and suggested WhatsApp is a powerful tool to enhance students' writing skills.

Elmedni, B., \& Lyons, B. P. (2015) came out with a study entitled Writing Skills Development for Graduate Students: Workshop Intervention Using a Student-Centered Learning Approach. Both quantitative and qualitative data was collected through a questionnaire administered on 156 students. A workshop based on student-centered learning was also conducted. This study revealed that the workshop showed a significant difference in developing writing skills.

Ahmed. M (2016) investigated the effect of using Facebook to develop grammar discussion and writing skills in EFL for University students through writing tests and using grammar. This study showed that the experimental group performed better than the control group, and their writing skills and grammar were also found to be improved.

According to Farooq (2012), grammar is the most challenging subject for $\mathrm{L}_{2}$ learners. Students have difficulties in applying proper sentence structure, developing paragraph writing skills and producing meaningful material. Run-on sentences, sentence patterns, subject-verb agreement, modifier placement, tense agreement and parallel construction are all types of grammar abilities. Grammar is more than just a set of rules; it is a living, breathing linguistic structure. For example, learners may understand how to construct sentences but struggle to apply them in written form in real life contexts. 


\section{RESEARCH OBJECTIVES}

The objectives of this study are to enhance writing skills of the ESL learners who face difficulties in learning them. The objectives are as follows:

1. To identify the difficulties faced by first- generation learners' writing skills.

2. To study the impact of difficulties on their writing skills.

3. To suggest solutions to enhance their writing skills.

\section{RESEARCH QUESTION}

What are the difficulties faced frequently by the first generation learner while writing and what can be the solutions to enhance his/her writing skills?

\section{SIGNIFICANCE OF THE STUDY}

The first generation learners in our country face many difficulties in developing writing skills in English. They do not know how to overcome these difficulties. They require a lot of practice and a few strategies to attain perfection in writing. The learners at the tertiary level, who hail from rural background in particular, are unable to write effectively. These students studied in nearby government schools most of which focus only on exams. So they have found it difficult to improve their writing skills. Some of the rural students might have studied in private schools but a majority of them had their mother tongue as medium of instruction. Since they have had less exposure to English, they come across a number of obstacles both in the written and spoken skills.

\section{METHODOLOGY}

This study was conducted to identify the difficulties in the writing skills of first-generation learners in English. The researchers made use of an exploratory methods strategy, acquiring quantitative data and interpreting the quantitative outcome with detailed qualitative data. Data were collected administering a questionnaire on the select first year graduate programme students who happened to be the first generation learners. As a follow-up to the quantitative result, a qualitative phase followed in order to explain the quantitative result. Creswell's mixed-method research technique model (2009) was used to create the framework for this research. In a quantitative study, a questionnaire is a common technique for gathering data. A questionnaire comprises a series of questions or statements that the respondent is required to indicate. The purpose of this study's questionnaire was to get students' opinions on the obstacles they confront with their English writing skills. The semi-structured interview is a well-known and reliable tool in qualitative research. It supplies investigators with specific and necessary information for analysis. A mixed-method of investigation combines or associates qualitative and quantitative research. It entails philosophical assumptions, qualitative and quantitative methods and the mixture of the two in a study. The concept and theme of the questionnaire were adopted and modified from the study undertaken by Farooq (2012). This study also investigated the opinions of second language learners about writing difficulties in English. And also, Akbar M (2017) studied these problems affecting learners' English writing skills in the public sector colleges of Hyderabad city, Sindh, Pakistan.

\section{SAMPLE AND SIZE}

Sampling is a crucial aspect of the research process because the entire outcome of the research depends on the participants. Therefore, the quality of research is determined not only by the data collection methodology used but also by the participants adopted for this study. The current study used random sampling to collect data. The sample consisted of 80 students of which boys and girls were equal in number (i.e. 40 from each gender). All these students were undergoing first year degree course in Economics and 
English, from National College of Arts and Science, and St. Ann's College of Arts and Science, in Tindivanam at the time of this experimentation and it was seen that the entire sample were from rural background till they had completed their school education and also that each of them was a first graduate learner.

\section{Questionnaire}

The sample was administered a five-point scale questionnaire with the following statements which attempted to gauge the learners' difficulties in developing writing skills.

\section{TABLE 1}

\section{CLASSIFICATION OF ITEMS IN THE QUESTIONNAIRE TO IDENTIFY THE} DIFFICULTIES IN DEVELOPING WRITING SKILLS

\begin{tabular}{|c|l|}
\hline S.No & \multicolumn{1}{c|}{ Statement } \\
\hline 1 & I don't have enough vocabulary to make sentences. \\
\hline 2 & I face some difficulty to spell new words. \\
\hline 3 & Whenever I find it difficult to write, I use only simple words to construct sentences. \\
\hline 4 & First I think in my mother tongue and then translate it into English. \\
\hline 5 & Tenses are difficult for me while writing sentences. \\
\hline 6 & I feel difficulty while transforming voice i.e. active to passive or vice versa. \\
\hline 7 & Grammatical mistakes are there when I express my ideas in English. \\
\hline 8 & I get low marks because of poor handwriting. \\
\hline 9 & I get low marks because of spelling mistakes. \\
\hline 10 & Whenever I write essays in English, I use my mother tongue first. \\
\hline 11 & It takes much time to recall the exact spelling. \\
\hline 12 & I do not like to repeat the same word but try its synonyms. \\
\hline 13 & Whenever I use punctuation marks in sentences, I get confused. \\
\hline 14 & I often complicate while mentioning the things which I have expressed earlier. \\
\hline 15 & It is quite difficult for me to understand somewhat longer sentences in English. \\
\hline 16 & My way of constructing sentences is not good. That's why I cannot speak well. \\
\hline 17 & I feel I cannot write sentences coherently. \\
\hline 18 & The wrong use of punctuation marks is the cause of my writing problems. \\
\hline 19 & I feel it difficult to use conditional clauses. \\
\hline 20 & As I am not good at using commas, my sentences do not convey the complete meaning. \\
\hline 21 & I can't write past events without grammar mistakes. \\
\hline 22 & I face some difficulty while connecting ideas in English. \\
\hline 23 & I often face complications to connect one paragraph to another one. \\
\hline 24 & I use my mother tongue whenever I can't find the correct English expression. \\
\hline 25 & I believe that reading short stories and newspapers will improve my vocabulary. \\
\hline
\end{tabular}

\section{Semi-Structured Interview}

The researchers carried out semi-structured interviews in order to analyze the perception of students' experience when researching writing skills. Ten students from the experimental group were interviewed for this study. A few questions related to learning activities were posed. Finally, an intervention strategy by way of remedial sessions for five hours at the rate of one hour per day was put in place so as to improve the writing skills of the first graduate learners. As a result, most of the students were found to have a positive impact on writing activities. 


\section{Pre-Test and Post-Test}

A pre-test and a post-test were conducted. During the pre-test, when the test sheet was given, the students showed difficulty in answering the questions. After necessary guidance through a programme of remedial teaching, the post-test proved that the intervention helped them improve. The researcher gave some reading and writing activities to the students. The researcher asked the students to underline difficult words and find their meanings after finding their meanings and again made them to read the same passage. The researcher asked them to make sentences of their own using those difficult words. These sentences had to be in simple structures. The researcher made them to write dialogues and asked them to do a role play. Some sets of words could be memorized through these activities.

\section{RESULT}

FIGURE 1

ANALYSIS OF THE FIRST-GENERATION LEARNER'S DIFFICULTIES IN WRITING ENGLISH: PRE - TEST

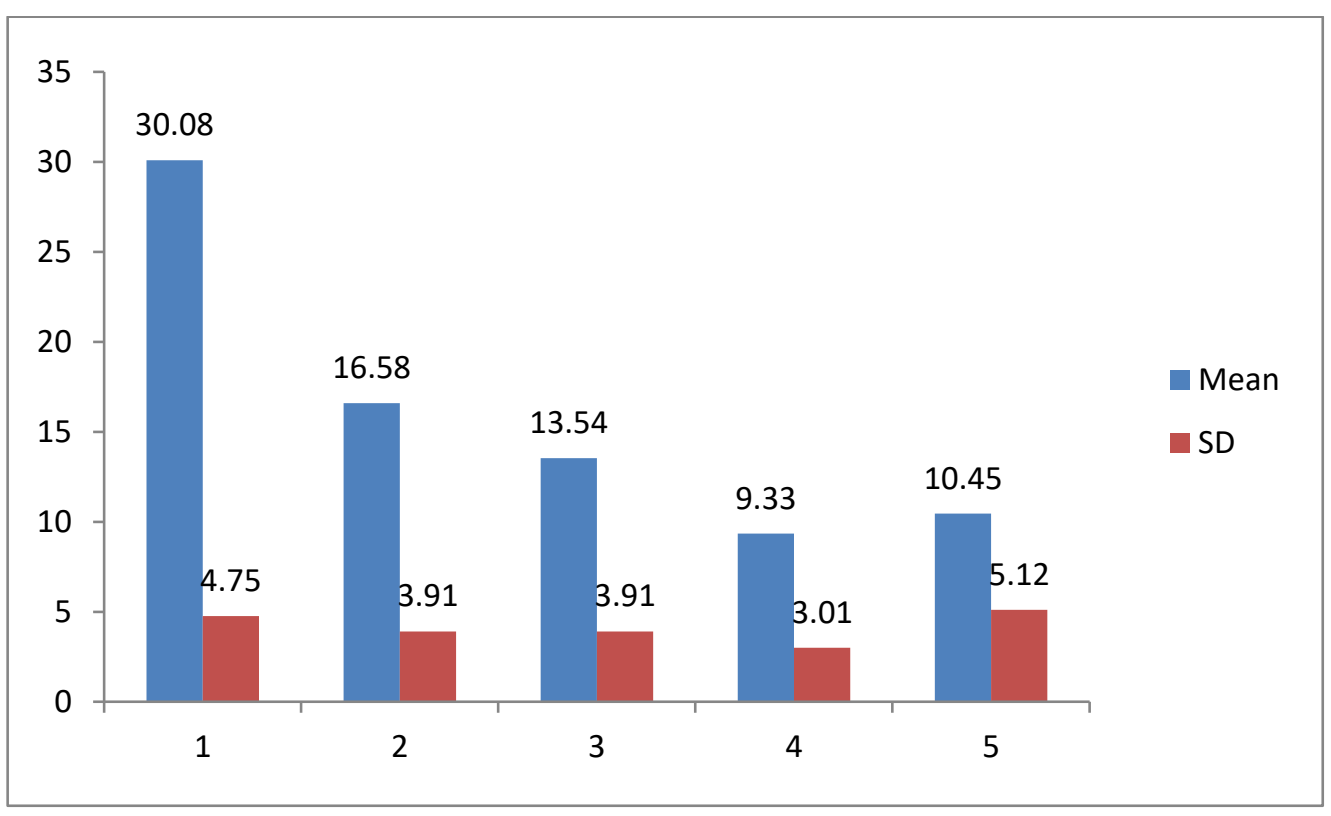

Figure1 describes the difficulties of first-generation learners across the five-point scale of strongly agree, agree, undecided, disagree and strongly disagree to the positive statements posed. Most of the students strongly agreed to a mean value of 30.08 and a standard deviation value of 4.75 . The agreed mean value was 16.58 and the standard deviation value was 3.91. The undecided mean value was 13.54 and the standard deviation value was 3.91. Disagreed mean value was 9.33 and standard deviation value was 3.01. Strongly disagreed mean value was 10.45 and standard deviation was 5.12. 


\section{FIGURE 2 \\ ANALYSIS OF THE FIRST-GENERATION LEARNER'S DIFFICULTIES IN WRITING ENGLISH: POST-TEST}

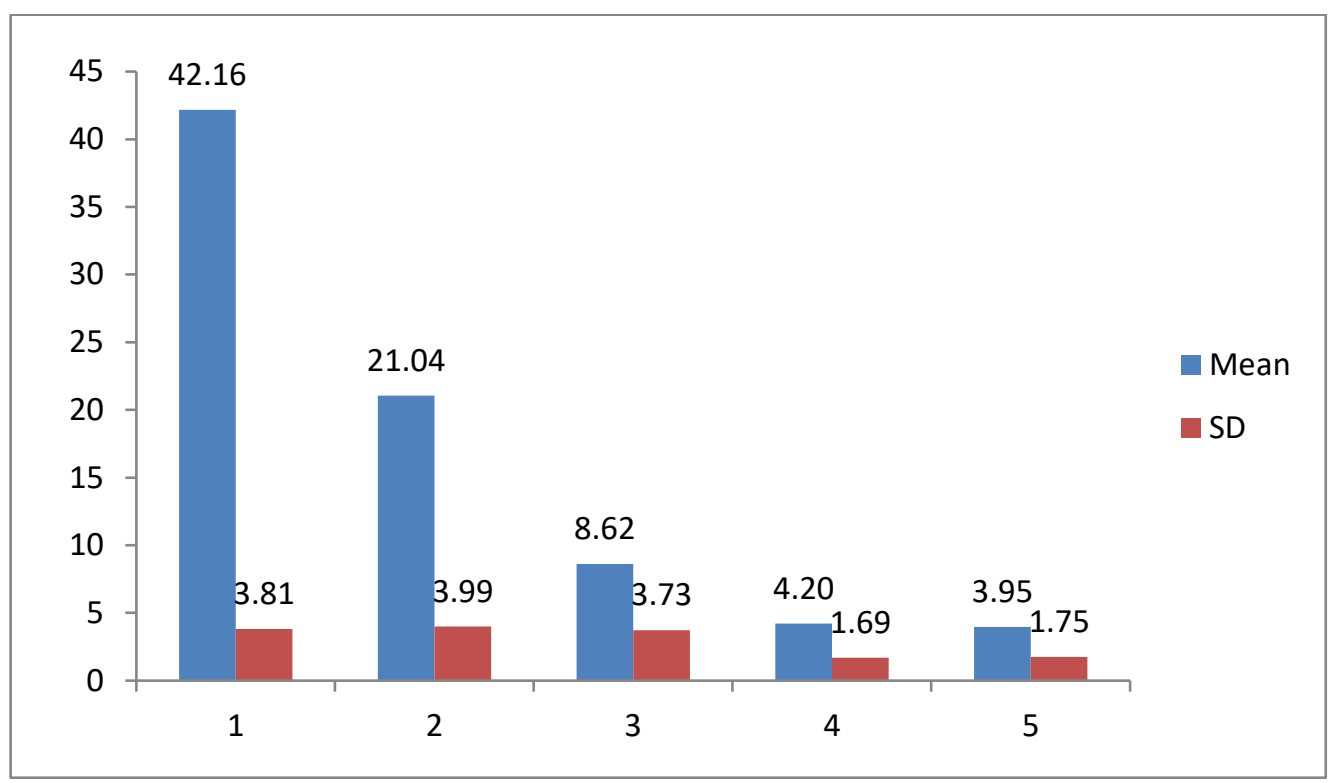

Figure 2 describes the post-test result and the majority of the students answered 'strongly agree'. Strongly agree mean value was 42.16 and the standard deviation value was 3.81. Agree mean value was 21.04 and the standard deviation value was 3.99. The undecided mean value was 8.62 and the standard deviation value is 3.73. Disagree mean value was 4.20 and the standard deviation was 1.69. Finally, the strongly disagree mean value was 3.95 and the standard deviation value was 1.75 .

\section{FINDING AND DISCUSSION}

The present study aimed at identifying the difficulties of first-generation learners in writing skills. The findings are related to the significance of the research and methodologies adopted. The mean value of the sample in the pre-test was 30.8, and the standard deviation value 4.75. After giving the intervention, the mean value became 42.16 and the standard deviation value 3.81. The researcher found that most of the students had given positive responses and developed their writing skills. And also, the researcher conducted a semi-structured interview for 10 students from the entire sample of the study. The researcher asked five questions to them. To the first question (How often do you commit mistakes while constructing sentences?), out of 10, six students answered very rarely and two students answered rarely. To the second interview question (How many words as an average do you use in a sentence?), eight students answered more than five words and two students answered more than four words. Responding to the third question (Can you recall when you were affected most by $L_{1}$ interference?), four students answered during the stage of primary schooling, four students answered during the elementary stage and only one answered during his higher secondary stage. To the fourth question (At what stage have you developed your writing skills?), four students said they developed their writing skills at the higher secondary stage and the remaining students said it happened after they completed their higher secondary course. To the last question (How many new words do you use as an average in a paragraph?), most of the students responded that they could use three or four new words in a paragraph.

It was inferred from the discussion with the sample group that improvements in English writing skills as remedial factors can be effective through the following measures:

i. Dictation 
ii. Writing exercises with topic allocation

iii. Reading for writing enhancement

iv. Vocabulary acquisition through writing

v. Using technology to help students enhance their writing abilities

\section{CONCLUSION}

Writing is a sophisticated form of self-expression as well as a literacy skill. The data analysis reflected the study's goal: learners were having some problems writing in English. The most common issue that Indian students encounter is that they think in their mother tongue first, then translate their ideas into English whose structure of grammar and nuances of imagery differ from Indian languages. The researchers found that most of the students have insufficient vocabulary, $\mathrm{L}_{1}$ interference and confusion in grammatical rules. The students feel a number of difficulties in writing when they face challenges in reading. Reading and writing are two reciprocal skills and develop simultaneously (Mubagna, 2010; Rummel, 2005). The difficulties in writing and speaking are also interrelated. The students should be trained to remember irregular spellings and spelling rules. Focus should be on grammar rules while teaching English. The instructor should as well concentrate on writing skills rather than oral skills. Based on the results, the researchers have found a positive impact on students' writing skills. The result indicated that most students responded positively during the semi-structured interview. The researchers made attempts to find some solutions to improve students' writing skills upon knowing the causes for some difficulties and came out with measures to enhance their writing skills through some writing activities.

\section{LIMITATION OF THE STUDY}

The current study was limited to the first graduation learner's difficulties in writing skills from rural backgrounds. Additionally, the paper gave suggestions to improve writing skills in English as remedial factors.

\section{REFERENCES}

Ahmed, M.A. (2016). Using Facebook to develop grammar discussion and writing skills in English as a foreign language for university students. Sino-US English Teaching, 13(12), 932-952.

Akbar, M., Pathan, H., \& Ali Shah, S.W. (2018). Problems Affecting L Learners' English Writing Skills: A Study of Public Sector Colleges Hyderabad City, Sindh, Pakistan. Language in India, 18(5).

Bakeer, A.M. (2018). Effects of Information and Communication Technology and Social Media in Developing Students Writing Skill: A Case of Al-Quds Open University. International Journal of Humanities and Social Science, 8(5), 45-53.

Daniels, P.T., \& Bright, W. (1996). The World's Writing Systems. London: Oxford University Press.

Elmedni, B., \& Lyons, B.P. (2015). Writing Skills Development for Graduate Students: Workshop Intervention Using a Student-Centered Learning Approach. Journal of Education \& Social Policy, 2(1), 38-49.

Farooq, M.S., \& Uzair-ul-hassan, M. (2012). Opinion of Second Language Learners about Writing Difficulties in English Language. Journal of South Asian Studies, 27(1), 183-194.

Gaikwad, J., \& Karekatti, T. (2018). Improving Writing Skills of Commerce Students. International Journal of English Language, Literature in Humanities, 6(5).

Geethanadani, K., \& Rajkumar, S. (2021). Comic Relief and Young Learners - How Exposure to Plays Will Influence their Intellect? International Journal of Early Childhood Special Education, 13(2), 1238-1244. https://doi.org/10.9756/int-jecse/v13i2.211171

Gomathi R.D., \& Radhakrishnan V. (2017). Improving the English Writing Skills of College Students through Activity Learning. International Journal of English Language, Literature in Humanities, $5(10)$. 
Jack, M. (2013). Factors Impacting Academic Writing Skills of English Second Language Students. Thesis submitted to Department of English, University of South Africa. DOI:10.5901/mjss,2013.v4n14p377

Justina, M. (2016). Use of WhatsApp to Enhance Reading and Writing Skills at Undergraduate College Level. Language in India, 16(11).

Perumal, K., \& Ajit, I. (2020). Enhancing Writing Skills: A Review. Psychology and Education Journal, 57(9), 2229-2236.

Shams, A., Khanam, A., \& Imtiaz, S. (2016). The Impact of Audio-Visual Aids and Graphic Organisers on the Writing Skills of ESL Learners at AMU +2 Girls. Global Journal of Interdisciplinary School Sciences, 5(5), 15-36. 